\title{
Metodologia da Pesquisa em Educação
}

\author{
Methodology of Research in Education
}

Metodología de la Investigación en Educación

Rosana Brandão Vilela ${ }^{1}$

O livro "Metodologia da Pesquisa em Educação" tem a proposta de ajudar os estudantes a desenvolverem competências e habilidades essenciais ao trabalho da pesquisa. Com 254 páginas, é dividido em doze capítulos, os quais tratam da abordagem teórica e exercícios práticos de cada etapa da pesquisa quanti e qualitativa. $\mathrm{O}$ primeiro - As diversas formas de ver o mundo - apresenta uma visão geral da busca incessante do homem para explicar os eventos que ocorrem na sua vida. Para tanto, recorre a mitos, religião, senso comum, filosofia e a ciência com seus tipos de raciocínios (indutivo, hipotético-dedutivo, analógico e reprodutivo) para se chegar a uma conclusão.
O autor do livro, pedagogo, mestre em administração de empresas, professor de metodologia da pesquisa de cursos de graduação e pósgraduação, Bruno Taranto Malheiros, convida o leitor a experimentar e se envolver com a pesquisa oferecendo orientações para estruturar uma investigação.

No capítulo 2 são apresentadas as questões das pesquisas científicas na área da educação, suas formas de classificação e os métodos que são utilizados para responder as questões. Discutem-se os tipos de avaliação do trabalho e as formas de comunicação do trabalho e seus aspectos éticos. O terceiro, juntamente com o quarto capítulo, abordam e orientam sobre o 
planejamento de uma pesquisa. $\mathrm{O}$ planejamento cuida desde a construção do problema científico, apresentação dos objetivos, formulação de hipóteses ou pressupostos, delimitação, justificativa e relevância e, por fim, a estruturação do projeto de pesquisa apresentado no capítulo 4.

No capítulo cinco, o autor apresenta os principais procedimentos técnicos para que a coleta de dados alcançarem os objetos de pesquisa da área de educação. As implicações do uso de cada um deles, considerando que sua escolha influência no resultado, e que deve ser permanentemente revisado durante toda a pesquisa. Em seguimento à estruturação da pesquisa, o capítulo seguinte - capítulo seis - aborda a fundamental etapa de construção do referencial teórico e seus desafios.

Os quatros capítulos que se seguem descrevem as etapas da coleta e análise de dados na abordagem quantitativa (7 e 8$)$ e qualitativa (9 e 10). São abordados, separadamente por questão de didática. Nesses capítulos, o autor propõe roteiros, sempre associados a problemas da prática na área de educação.

$\mathrm{Na}$ leitura do capítulo nove o leitor, facilmente, assimila a construção da informação qualitativa, contribuindo para sua compreensão das características, especificidades e procedimentos, podendo utilizá-la quando estiver diante de temas que se interessam mais pela intensidade do que pela quantificação da realidade.

O conteúdo do capítulo dez sugere formas de superar os obstáculos encontrados na análise de conteúdo, como adotar as categorias a partir do seu objetivo, comprometido com o desenvolvimento de suas ideias emergentes, para garantir qualidade dos dados obtidos, ou seja, a sua relevância e utilidade.

Mesmo tratando as abordagens em capítulos separados, o autor realça que métodos quantitativos e qualitativos muitas vezes são tomados como complementares, já que qualidade e quantidade são faces distintas de um mesmo fenômeno.

No penúltimo capítulo do livro, o autor sustenta a importância da construção do relatório final de pesquisa. $\mathrm{O}$ livro termina com o capítulo doze onde são apresentados, de forma didática, os principais tipos de trabalho acadêmico utilizando, como modelo, a regulamentação da Associação Brasileira de Normas Técnicas (ABNT).

Portanto, trata-se de obra que explora a metodologia da pesquisa na área da educação com cuidado e 
didática. O domínio do tema, pelo o autor, foi demonstrado pela apropriação dos conceitos, dos procedimentos acadêmico-científicos e, mais do que isso, dos modos de propor, sempre: um exercício de aplicação e perguntas provocativas para debates, ao final de cada capítulo, acompanhadas de um resumo executivo e uma avaliação de conhecimentos.

Este livro apresenta especial interesse para estudantes e pesquisadores, principalmente, mas não apenas, da área de educação. Pelo estilo e linguagem, pode ser utilizada tanto na graduação como na pós-graduação, enquanto modelo, do ponto de vista metodológico.

\section{Referência}

1. Santos MFR. Metodologia da Pesquisa em Educação. São Luís: UEMANET; 2010. 